\title{
Heat Transfer Characteristics of Flooded Type Evaporator for Seawater Cooling System
}

\author{
Jung-In Yoon ${ }^{1}$, Chang-Hyo Son ${ }^{1}$, Hyung-Min Han ${ }^{2}$, Kwang-Seok Lee ${ }^{2, a}$, Jung-Mok Lee ${ }^{3}$, In-Duck You ${ }^{3}$ \\ ${ }^{1}$ Department of Refrigeration and Air-conditioning Engineering, College of Engineering, Pukyong National University, \\ San 100, Yongdang-dong, Nam-gu, Busan, 608-739, South Korea \\ ${ }^{2}$ Graduate School, Pukyong National University, San 100, Yongdang-dong, Nam-gu, Busan, South Korea \\ ${ }^{3}$ Korea Seal Tech, 26, Sinhosandan 3-ro 88beon-gil, Gangseo-gu, Busan, South Korea
}

\begin{abstract}
In these days, many studies on ocean fisheries have been conducted for developing their own industries. Especially, the efforts of using seawater cooling system were actively conducted to keep the caught fisheries fresh, increase the catches, and decrease the manpower. The purpose of this study is to suggest design criteria of seawater cooling system using the flood-type evaporator. In this study, the seawater cooling system using flooded-type evaporator was manufactured as a prototype capacitating $15 \mathrm{~kW}$. This study examined performance of the seawater cooling system and then compared the performance with the system capacitating $163 \mathrm{~kW}$ and $238 \mathrm{~kW}$, which is actually being loaded on the fishery boats. In addition, heat transfer characteristics of the flooded-type evaporator used in the equipment are analysed.
\end{abstract}

\section{Introduction}

Due to production decrease with purse seine fishery and unstable supply of fish, it is suggested to find ways to improve freshness of fish to increase fishery amounts and decrease manpower. It is important to keep temperature constant in fish storage in order to improve freshness of the caught fish. Hence, many researches on ice making machine and seawater cooling system have been actively conducted. Normally, there are two ways to refrigerate the fish storage. The first one is to use fresh water ice, which is very popular way. However, this may damage the fish due to the weight and sharpness of ice, and also it is difficult to adjust salinity in the storage. The second way is to utilize seawater cooling system on the boats and it doesn't damage the fish. This also can lengthen the fishing hours and decrease manpower to keep the caught fish fresh. Previous research on seawater cooling system used flooded-type evaporator to enhance the performance of the system. These relevant studies are as follows.

Yoon et al. [1] evaluated performance characteristics of flooded type evaporator for fishery vessels using R22 and R134a. They analysed heat transfer coefficient of manufactured tube with respect to heat flux, chilled water temperature and velocity of chilled water etc. As a result, the study suggested guideline of chilled seawater velocity, temperature and heat transfer coefficient of manufactured tube for the flooded type evaporator.

\footnotetext{
${ }^{a}$ Corresponding author : suwe1862@gmail.com
} 
Jung et al. [2] conducted the heat transfer coefficient experiment with respect to working fluid. Also, the study compared heat transfer characteristics of plain tube, 26fpi low-fin tube, Turbo-B tube, and Thermoexcel-E tube with regard to heat flux by using electric heater.

Kim [3] examined the effect of oil on boiling in flooded-type evaporator by experiment. As a result, when oil occupies less than $1 \%$ of the portion, overall heat transfer efficiency decreased dramatically. However, the overall heat transfer coefficient decreased gradually when oil occupies over $1 \%$ of the portion.

Based on these studies, applying seawater cooling system on the boat is more efficient to keep temperature constant in fish tank. This research also analysed heat transfer characteristics with regard to the tube materials of flooded type evaporator through the experiments. In addition, the research examined the system performance of the seawater cooling system applied to the flooded type evaporator. Therefore, this research suggests that the heat transfer characteristics of flooded type evaporator need to be examined and designing the seawater cooling system applied flooded type evaporator is critically important.

\section{Experiment and Analysis condition}

\subsection{Experimental apparatus}

\subsubsection{Flooded type evaporator}

Fig. 1 shows experiment apparatus of the flooded type evaporator applied to seawater cooling system and piping and instrumentation schematic diagram. Compositions of the flooded type evaporator apparatus are flooded type evaporator, double pipe type condenser, receiver and pump. Operating principle of the apparatus is as follows. The refrigerant at the receiver flows into the evaporator by pump, and evaporates by exchanging heat with the seawater inside the evaporator. The evaporated gaseous refrigerant flows into the double pipe type condenser located on the evaporator, and is condensed by cooling water.

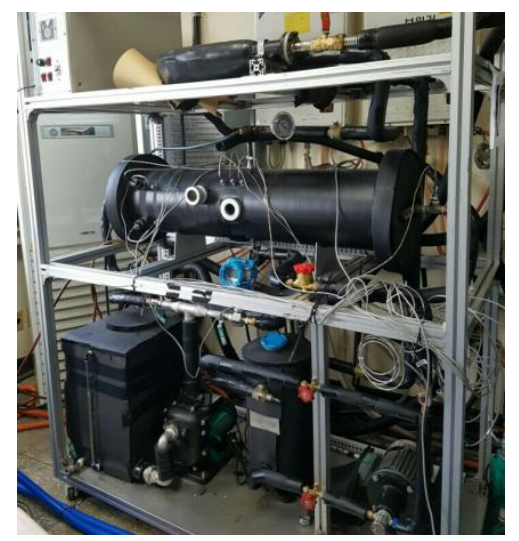

Figure 1. Piping and instrumentation schematic diagram and Experimental apparatus of the flooded type evaporator.

\subsubsection{Seawater cooling system}

Fig. 2 shows experiment apparatus and piping and instrumentation schematic diagram of the seawater cooling system applied the flooded type evaporator. The apparatus are composed with the flooded type evaporator, open-type reciprocating compressor, condenser, receiver, expansion valve, oil recovery heat exchanger, surge drum, separator and oil return collector. Working principle of the 
system is as follows. Gaseous refrigerant with high temperature and high-pressure from the compressor outlet flows into the condenser. Liquid refrigerant condensed by the cooling water flows to the oil recovery heat exchanger, and evaporates at the evaporator. After the evaporator, the refrigerant flows to compressor inlet.

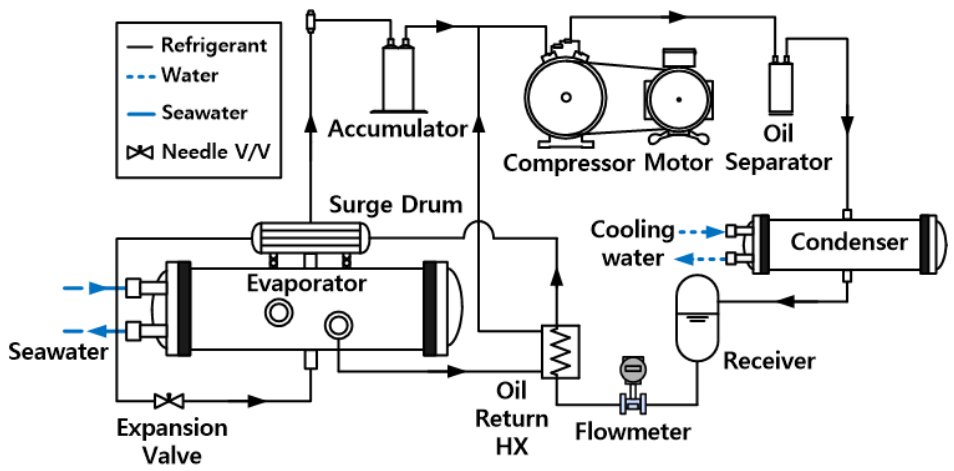

Figure 2. Schematic diagram of seawater cooling system.

\subsection{Experimental and analysis condition}

Table 1 shows analysis condition and the experimental condition of both evaporator heat transfer performance characteristics and the seawater cooling system. Working fluids are R134 and R22, and the experiment conditions are set up as follows. The seawater inlet and outlet temperature are set up as $5^{\circ} \mathrm{C}$ and $3^{\circ} \mathrm{C}$ respectively in the experiment of the seawater cooling system. The outlet temperature depends on kinds of fish in fish tank. This study assumed to refrigerate external blue colored fish in fish tank, so storage temperature is set up as $3^{\circ} \mathrm{C}$ by default. The cooling water temperature has range of temperature from $19^{\circ} \mathrm{C}$ to $29^{\circ} \mathrm{C}$ based on surface seawater mean temperature $25^{\circ} \mathrm{C}$. Also, if compressor operates with same rotation speed for both refrigerants, compressor overload due to increase of condensation pressure. So in order to prevent compressor overload and maintain same condensation pressure for both refrigerants, the compressor rpm should be set up differently for refrigerant. Therefore, compressor rpm is set up as $40 \mathrm{~Hz}$ for $\mathrm{R} 22,60 \mathrm{~Hz}$ for R134a.

Table 1. Experimental and analysis condition.

\begin{tabular}{cccc}
\hline Parameter & $\begin{array}{c}\text { Flooded type } \\
\text { evaporator }\end{array}$ & $\begin{array}{c}\text { HYSYS } \\
\text { simulation(15kW) [4] }\end{array}$ & $\begin{array}{c}\text { Seawater cooling } \\
\text { system(15kW) }\end{array}$ \\
\hline Refrigerant $[-]$ & R134a, R22 & R134a, R22 & R134a, R22 \\
Chilled seawater inlet temperature $\left[{ }^{\circ} \mathrm{C}\right]$ & $5 \sim 25$ & 5 & 5 \\
Chilled seawater outlet temperature $\left[{ }^{\circ} \mathrm{C}\right]$ & - & 3 & 3 \\
Evaporating temperature $\left[{ }^{\circ} \mathrm{C}\right]$ & $-5 \sim 15$ & - & - \\
Cooling water inlet temperature $\left[{ }^{\circ} \mathrm{C}\right]$ & - & $19 \sim 29$ & $19 \sim 29$ \\
Velocity of chilled seawater $[\mathrm{m} / \mathrm{s}]$ & 1.8 & - & - \\
Inverter frequency $[\mathrm{Hz}]$ & - & - & 60,40 \\
\hline
\end{tabular}

\subsection{Data analysis}

The properties of the refrigerants used in this study are based on the REFPROP program of NIST [5], and the following equations were applied to determine the heat transfer characteristics of the floodtype evaporator.

First, Eq. (1) was applied to calculate the evaporation capacity. In the equation, the mass flow rate of the seawater flowing into the tube was multiplied by the temperature difference between the inlet and outlet. Eq. (2) was used to calculate COP of the seawater cooling system. 


$$
\begin{gathered}
Q_{e}=G_{c s w} C_{p, c s w}\left(T_{c s w, \text { in }}-T_{c s w, o u t}\right) \\
\operatorname{COP}=\frac{Q_{e}}{W}
\end{gathered}
$$

Eq. (3) was used to calculate the overall heat transfer coefficient. Here, the evaporation capacity $\left(Q_{e}\right)$ can be obtained from Eq.(2) above, and $A_{o}$ can be obtained from the specification data of the tube.

$$
U_{o}=\frac{Q_{e}}{A_{o} \cdot \Delta T_{L M T D}}
$$

The overall heat transfer coefficient $\left(\mathrm{U}_{\mathrm{o}}\right)$ of the flood-type evaporator can be obtained from Eq. (4), and the resistance of heat conduction $\left(R_{w}\right)$ of the tube can be computed using Eq. (5).

$$
\begin{gathered}
\frac{1}{U_{o} A_{o}}=\frac{1}{h_{i} A_{i}}+R_{w}+\frac{1}{h_{o} A_{o}} \\
R_{w}=\frac{\ln \left(d_{o} / d_{i}\right)}{2 \pi L k}
\end{gathered}
$$

The heat transfer coefficient $\left(\mathrm{h}_{\mathrm{i}}\right)$ of the seawater can be obtained from the Dittus-Boelter equations shown in Eq.(6) (8), which illustrate the correlation applicable to the convection heat transfer of a single phase liquid with turbulent flow. The heat transfer coefficient $h_{o}$ can be calculated using Eq.(4).

$$
\begin{gathered}
N u_{i}=0.023 \operatorname{Re}^{4 / 5} \operatorname{Pr}^{0.3} \\
R e_{i}=\frac{\rho v L}{\mu} \\
N u_{i}=\frac{h_{i} L}{k}
\end{gathered}
$$

\section{Experiment result}

\subsection{Heat transfer coefficient experiment with respect to evaporating temperature}

The flooded type evaporator experiment was conducted with the condition that inlet temperature and velocity of the chilled seawater were each $10^{\circ} \mathrm{C}, 1.8 \mathrm{~m} / \mathrm{s}$. Also, R134a and R22 were used as working fluids. Aluminum-brass tube and copper-nickel tube were applied to this experiment, and the heat transfer coefficients of those were obtained. As a result, when evaporating temperature decreases, heat transfer coefficient tends to increase as shown in Fig. 3. Also, the heat transfer coefficient increased $76.6 \%$ on average as the evaporating temperature decreased from $5^{\circ} \mathrm{C}$ to $-5^{\circ} \mathrm{C}$. It was analyzed as the cause that increment of the evaporation capacity was larger than that of the mean temperature difference. Besides, difference of heat transfer coefficient for refrigerants was $0.35 \mathrm{~kW} / \mathrm{m}^{2} \mathrm{~K}$ when same material tube used. Difference of the coefficient for tube materials was $0.25 \mathrm{~kW} / \mathrm{m}^{2} \mathrm{~K}$ when same refrigerant used. These values were not presented largely, because the heat capacity was calculated by short tubes of $1 \mathrm{~m}$.

\subsection{Evaporating and seawater outlet temperature with respect to cooling water temperature for flooded type evaporator}

Fig. 4 shows the seawater outlet temperature and evaporating temperature with respect to cooling water temperature in flooded type evaporator experiment. The chilled seawater outlet temperature 
showed range from $2.2^{\circ} \mathrm{C}$ to $3.4^{\circ} \mathrm{C}$ for $\mathrm{R} 134 \mathrm{a}$, and the average value was $2.85^{\circ} \mathrm{C}$. For $\mathrm{R} 22$, range of the temperature had from $2.8^{\circ} \mathrm{C}$ to $3.2^{\circ} \mathrm{C}$ and the mean temperature was $3.06^{\circ} \mathrm{C}$. These range of the chilled

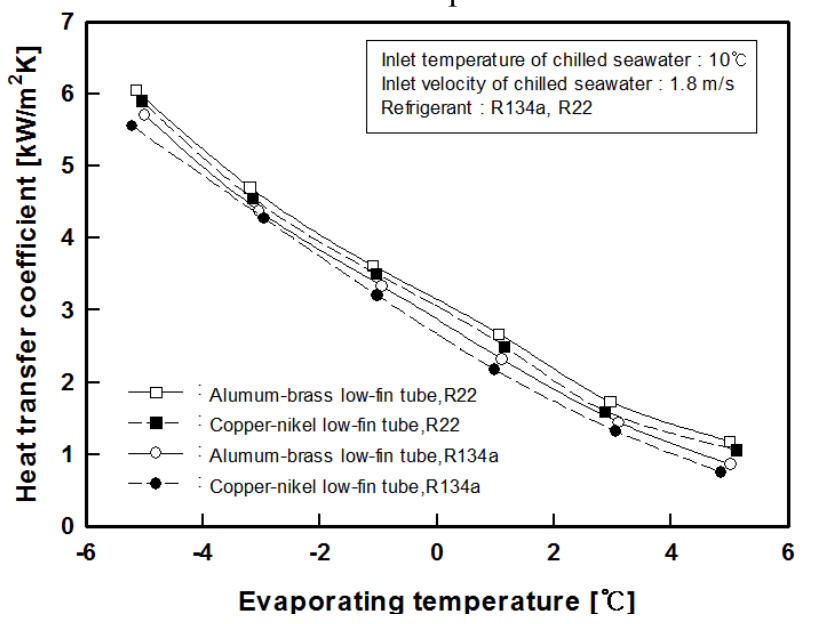

Figure 3. Heat transfer coefficient with regard to evaporating temperature for flooded type evaporator experiment.

seawater outlet temperature satisfied quantitative desired range from $2^{\circ} \mathrm{C}$ to $4^{\circ} \mathrm{C}$. Furthermore, the evaporating temperature was set as saturation temperature from REFPROP program by evaporation pressure measured. Consequently, all values of the evaporating temperature satisfied the quantitative desired value of that under $0^{\circ} \mathrm{C}$. In the case using R134a, minimum of evaporating temperature was $2.6^{\circ} \mathrm{C}$ and maximum of that was $-1.8^{\circ} \mathrm{C}$, and the mean value was $-2.2^{\circ} \mathrm{C}$. On the other hand, the case using R22 showed $-5.01^{\circ} \mathrm{C}$ as value of minimum and $-2.8^{\circ} \mathrm{C}$ as value of maximum. The average evaporating temperature for $\mathrm{R} 22$ was $-3.9^{\circ} \mathrm{C}$.

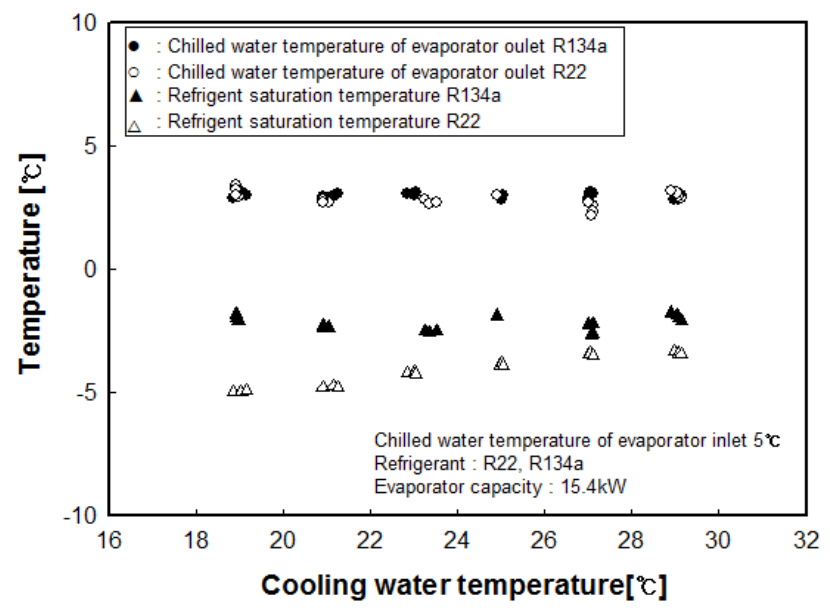

Figure 4. Seawater outlet temperature and evaporating temperature of refrigerant.

The COP of the $15 \mathrm{~kW}$ seawater cooling system is shown at Fig. 5. When the cooling water temperature increases, evaporation capacity for R134a tended to increase slightly. Moreover, compressor consumption power rose up about $14.4 \%$. As a result, COP tended to decrease, and the decrement presented $12 \%$ and $11 \%$ from the experiment and HYSYS analysis each. For R22, while the evaporation capacity increased approximately $10 \%$, the increase of the compressor consumption power was larger $16.2 \%$. As a result, COP tended to decrease for R22 and the decrement showed 19\% and $10 \%$ from the experiment and HYSYS analysis each. 


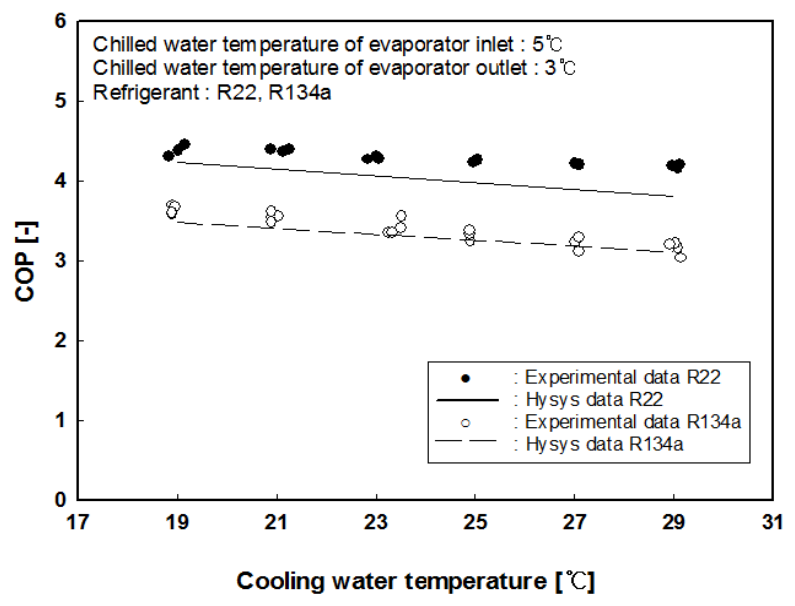

Figure 5. COP of $15 \mathrm{~kW}$ seawater cooling system with respect to cooling water temperature.

\section{Conclusions}

The summary of the experimental results is as follows.

From the heat transfer coefficient experiment with respect to evaporating temperature for flooded type evaporator, aluminium-brass low-fin tube had higher heat transfer performance than coppernickel low-fin tube. Also, R22 as working fluid showed higher heat transfer performance than R134a.

From the heat transfer coefficient experiment with regard to evaporating temperature for $15 \mathrm{~kW}$ Seawater cooling system, heat transfer performance of aluminium-brass low-fin tube changed as the temperature level of both evaporating temperature and chilled seawater inlet temperature changed. The heat transfer was occurred actively at high temperature level, and the molecular motion and the surface tension were factors to effect on the heat transfer critically.

From the experiment on evaporating and seawater outlet temperature with respect to cooling water temperature for flooded type evaporator, the result of the chilled seawater outlet temperature satisfied the quantitative desired chilled seawater outlet temperature of $3{ }^{\circ} \mathrm{C}$ at all range of the cooling water temperature. Also, the result of the evaporating temperature presented under $0^{\circ} \mathrm{C}$ as the quantitative desired range as well.

The COP with respect to cooling water temperature for seawater cooling system was examined in this experiment, and showed decrease of $19 \%$ for $\mathrm{R} 22$ from $19^{\circ} \mathrm{C}$ to $29^{\circ} \mathrm{C}$ of the cooling water temperature.

\section{Acknowledgement}

This research was a part of the project titled 'Introduction study of seawater cooling system for fishing-ships', funded by the Ministry of Oceans and Fisheries, Korea.

\section{References}

1. J. I. Yoon, C. H. Son, K. H. Choi, S. H. Jung, H. M. Han, S. H. Seol, Heat transfer engineering(to be published)

2. D. S. Jung, K. Y. Park, J. S. Park, Intl. J. of Refrigeration, 27, 8, 710-720 (2001)

3. S. G. Kim, MS thesis, Pusan University, Busan, Korea (2011)

4. Aspentech HYSYS 8.6

5. REFPROP, Version 8.0, NIST Inc, 2007. 